\title{
Discussion on the English Teaching Mode of Traditional Chinese Medicine
}

\author{
Wang Xiaofang, Liu Cheng \\ School of Humanities, Jiangxi University of Traditional Chinese Medicine, Nanchang 330004, China \\ 920711622@qq.com,jxjzlc@163.com
}

\begin{abstract}
At present English Teaching in China mostly adopts the traditional way of teaching, and it still needs to be studied and improved. Based on the characteristics of the current college students in China, this paper constructs a new English teaching model of traditional Chinese medicine characteristics. Colleges and universities of traditional Chinese medicine should do more thinking and exploration in enhancing teachers' comprehensive quality, improving teaching objectives and teaching mode, cultivating students' professional English application ability. This new teaching model aims to provide reference for Chinese University English teaching reform.

Index Terms - The characteristics of traditional Chinese medicine, professional English teaching model
\end{abstract}

\section{Introduction}

Traditional Chinese medicine and Western medicine are two medical systems which coexist in the world, which are rooted in different cultural background and philosophy, through different roads of historical development. They are mutual independent and fusion. Because of modern China's complex social and historical environment, western medicine spread in China rapidly and extensively. Compared with western medicine, the influence and application of TCM is not satisfactory, which has a great relation with the foreign language ability of professional talents of TCM. China is the birthplace of traditional Chinese medicine. Chinese medicine colleges and universities are the cradle of training medical talents and spreading the culture of TCM. How to cultivate the high-quality and international talents of TCM, the key lies in the organic combination of TCM specialized knowledge and English teaching. Culturing the skilled talents of grasping the knowledge of TCM and professional English expression ability, is a necessary condition for TCM to enter the international stage and it is also a teaching task for universities of TCM to carry out in recent years.

\section{A. Improving the professional English level of TCM professional teachers}

Professional teachers is their enlightenment for students of TCM and open "the first door" to internationalization. How to cultivate international talents of TCM, the key lies in the English literacy of professional teachers and the proper application in teaching. Teachers should grasp the two key aspects in the cultivation of students' English ability: one is the cultural differences between Chinese and Western medicine which is deeply rooted, the other is the standardization of Chinese medicine terminology. The former focuses on understanding, while the latter focuses on memory. The former is more important for students, because the biggest difference of TCM and Western medicine is that TCM has the inherent unique theoretical system and language features ${ }^{[1]}$.

English often lacks direct correspondence words with TCM terminology vocabulary. Teachers should first teach students the official terminology. For some terminology that is hard to explain by using off-the-peg vocabulary terms, teachers should explain to the students by their theory of TCM combined with the practical application ${ }^{[2]}$. For example, in human anatomy structure and expression, Chinese medicine and Western medicine have unified part, such as: Chinese eyes, ear, nose, tongue, mouth, hair, skin, limbs represent the same position in anatomy in Western medicine. However, there is great difference between expressions on main viscera and collateral channels of TCM and visceral and circulatory system of Western Medicine, such as: the heart, liver, spleen, lung, and kidney. In TCM, the five internal organs (heart, liver, spleen, lung, kidney) refers to five different functional system; while in western medicine these words are true visceral organs. So teachers should not simply use the five organs of Western medicine to represent the main viscera in translating $\mathrm{TCM}^{[3]}$.

Therefore, relative departments should often organize the seminar, launches the research and study of professional vocabulary presentation of TCM and the similarities and differences of Chinese and Western medicine.

\section{B. Improving the TCM knowledge of English teacher}

English Teaching in Higher Institutions of Chinese medicine is mainly divided into two parts: general English and special English. Special English learning is based on general English $^{[4]}$. And the requirements of special English teachers' quality of TCM should be distinguished from general English teachers, and they should improve the medical knowledge. Only special teachers have a deeper understanding of TCM, can they do a more detailed preparation and promote students' learning.

When students have to learn the Yin-Yang, the five elements, hundreds of Chinese herbal medicines, hundreds of prescriptions and acupuncture point, they will put a lot of time for memory and comprehension TCM and do not have enough time to learn special English. Special English teachers should use the English way of thinking to explain TCM to help students to consolidate and deepen the knowledge. 


\section{Optimization of English teaching mode}

\section{1) Improving the mode of general English teaching}

Most of China's Colleges of TCM employ class teaching and general English teaching mode. Curriculum design of this mode is suitable for English majors, but it cannot achieve the desired effect of Non-English Majors. Students often learn English to pass the final examinations, CET-4 and CET-6, and do not lay a solid foundation for special English learning. Teachers should make full use of multimedia teaching and the internet, and mix the medical knowledge with the social, cultural customs of Western countries, such as ask students to watch TV medical subjects such as "House M.D", "Coma", "CIS" and "Grey's Anatomy". To improve the students' interest in English learning, teachers can increase dialogues and exchanges on health, medical and health care ${ }^{[5]}$. In the exercise of the scene mode, teachers should guide the students to summarize the encountered terminology in the context. In the end teachers evaluate on students' English application ability and special vocabulary ability, and points out their advantages and disadvantages to guide the students to learn English on purpose. This English Teaching mode in Colleges and universities of TCM are summarized in Table 1.

Table 1

\begin{tabular}{|c|c|c|c|c|c|}
\hline \multicolumn{2}{|c|}{ Time } & Content of Teaching & Teaching Methods & Teaching Objectives & Inspection \\
\hline \multirow{2}{*}{ First grade } & First semester & $\begin{array}{l}\text { Vocabulary and text } \\
\text { learning }\end{array}$ & $\begin{array}{l}\text { Teacher teaching and students } \\
\text { examine each other }\end{array}$ & $\begin{array}{l}\text { Achieves the vocabulary amount of } \\
\text { CET- } 4\end{array}$ & Vocabulary test \\
\hline & $\begin{array}{l}\text { Second } \\
\text { semester }\end{array}$ & Reading and listening & Multi-media and the internet & $\begin{array}{l}\text { Read English newspapers and } \\
\text { communicate in English }\end{array}$ & Reading time on English newspapers \\
\hline \multirow{2}{*}{ Second grade } & First semester & Health topic discussion & $\begin{array}{l}\text { Classroom interaction, group } \\
\text { interaction }\end{array}$ & $\begin{array}{l}\text { Familiar with medical health care } \\
\text { topics and common expressions, being } \\
\text { interested in special English }\end{array}$ & $\begin{array}{l}\text { Numbers and activity on discussion } \\
\text { topics }\end{array}$ \\
\hline & $\begin{array}{l}\text { Second } \\
\text { semester }\end{array}$ & $\begin{array}{l}\text { drills and dialogues of } \\
\text { professional medical } \\
\text { situation }\end{array}$ & $\begin{array}{l}\text { classroom interaction, extra- } \\
\text { curricular scene simulation }\end{array}$ & $\begin{array}{l}\text { Preliminary with professional quality, } \\
\text { expressing accurate knowledge and } \\
\text { clear of the objective of ESP learning }\end{array}$ & $\begin{array}{l}\text { Frequency and participation time } \\
\text { sum on scene mode and dialogue }\end{array}$ \\
\hline
\end{tabular}

\section{2) Optimization of special English teaching mode}

Special English is the application and improvement stage of general English. After a medical professional knowledge and the basic stage of English learning, English teaching should be more "Chinese characteristics". English teaching should also have "monarch, minister, assistant, make" division. Language is the carrier of culture, and it is a way of cultural dissemination and communication. The knowledge of traditional Chinese pharmacy should be in the "monarch" position in the entire process of TCM English Teaching, only after the fully understanding of TCM can we achieve accurate translation. The special English terminology is in the "minister" position. English translations with professional terminology can express TCM knowledge accurately and exert the advantages of TCM to serve the medical care ${ }^{[6]}$. Therefore, English teaching should guide the students to master special English in the analysis and differentiation of the basic theory of TCM. TCM emphasizes "the unity of heaven and man" which is a complex system and is difficult to analyze or study the human or disease as mechanical problems. Teachers can use specific disease descriptions to help students understand the abstract theory of TCM, such as "Gan Hui Wu Pi"(the specific pathological features of liver depression spleen). In the theory of TCM, anger or virus can cause the damage of liver function, thus affecting the secretion of bilification and causing dyspepsia. Patients often lose appetite, sallow complexion, emaciation and other symptoms. In the theory of TCM liver belongs to wood, and spleen belongs to earth.
Wood has an restrictive effect of earth. Compared with pure professional vocabulary memory and mechanical translation, this scientific analysis on the teaching mode can improve the students' learning interests and guide the students to learn to think in English to understand and explain Chinese abstract concepts.

\section{Carrying out special English activities after class actively}

In today's university campus, the student association activities and the variety of after class activities become a major project to college students' communication and entertainment. With the development and popularization of English radio station, English corner and other organization's activities, they have become an important platform for more and more college students to learn English. English Teaching in Colleges and universities of TCM should not only confined to the classroom, English Department should actively organize the after class activities that relates to TCM. For example, in the campus students can open simulation "overseas Chinese medicine clinic", and learn interactively with the oversea students. Encourage students to play their roles in the activity and let them learn knowledge more vividly.

\section{Conclusion}

Special English teaching of TCM starts later than other special English, colleges should encourage teachers to express personal views and opinions and urge them to summarize the teaching experience. Teachers should guide students to master 
the practice skills and self-study ability of TCM English translation. In addition, we should invite foreign sinologists and Chinese medicine experts to exchange the experience which has important significance for TCM English teaching.

\section{References}

[1] Mao Ying, Investigation of the Problems in English Teaching in TCM co lleges in the new period, Chinese Higher Medical Education, 2001, 1: 38 -39 .

[2] Zhang Fenxi, Yan Yuzhi, Investigation of Problems and Countermeasure s of University English Teaching. Chinese Higher Education, 2001, 17 (3): $52-55$.
[3] Zhao Bo, Anatomy History Comparison of Traditional Chinese Medicine and Western Medicine and their Theory System Construction [J]. China Journal of traditional Chinese medicine and Western medicine history of, 2003, 33 (3): 145-148.

[4] Zhou Yuehong, English Teaching in TCM colleges should attach importa nce to the fostering of application ability. Journal of Shanxi Medical Uni versity (Medical Education Edition) 2004, 6 (2): 218-219.

[5] Yang Zhengzheng, Comparative Research on related questions of TCM a nd Western medicine. Journal of Hunan traditional Chinese medicine, 20 07, 2 (13): 18-27.

[6] Wang Liguo, Similarities and Differences of Traditional Chinese Medici ne and Western Medicine. Pharmaceutical Forum, 2006, 3 (19): 93-96. 